\title{
Impact of pyrazinamide resistance on multidrug-resistant tuberculosis in Karakalpakstan, Uzbekistan
}

\author{
J. Kuhlin, ${ }^{*}$ C. Smith, ${ }^{*}$ A. Khaemraev, ${ }^{\dagger}$ Z. Tigay, $^{\dagger}$ N. Parpieva, ${ }^{\ddagger}$ M. Tillyashaykhov, ${ }^{\ddagger}$ J. Achar, ${ }^{\S}$ \\ J. Hajek, ๆ J. Greig,§ P. du Cros,§ D. Moore* \\ *London School of Hygiene \& Tropical Medicine, London, UK; ${ }^{\dagger}$ Ministry of Health, Nukus, ${ }^{\ddagger}$ Ministry of Health, \\ Tashkent, Uzbekistan; \$Medécins Sans Frontières, Manson Unit, London, UK; "University of British Columbia, \\ Vancouver, British Columbia, Canada
}

S U M M AR Y

SETtING: The World Health Organization (WHO) recommends the inclusion of pyrazinamide (PZA) in treatment regimens for multidrug-resistant tuberculosis (MDR-TB) unless resistance has been confirmed.

OBJECTIVE: To investigate the association between PZA susceptibility and MDR-TB treatment outcome among patients treated with a PZA-containing regimen and whether the duration of the intensive phase of the PZA-containing regimen affected treatment outcome. DESIGN: We conducted a retrospective cohort study including all eligible MDR-TB patients starting treatment in 2003-2013 in the TB programme in Karakalpakstan, Uzbekistan. PZA drug susceptibility testing (DST) using liquid culture was performed, and outcomes were classified according to the WHO 2013 definitions. RESULTS: Of 2446 MDR-TB patients included, 832
$(34.0 \%)$ had an available baseline PZA DST result, 612 $(73.6 \%)$ of whom were PZA-resistant. We found no association between treatment success and PZA susceptibility (adjusted odds ratio [aOR] 0.86, 95\%CI 0.51$1.44, P=0.6)$ in patients treated with PZA. Furthermore, among patients with no baseline PZA DST result, no evidence was seen of an association between treatment success and PZA treatment duration (aOR $0.86,95 \%$ CI $0.49-1.51, P=0.6$ ).

CONCLUSION: Treatment of MDR-TB with a standard PZA regimen does not appear to improve treatment outcomes, regardless of PZA susceptibility or duration of treatment.

KEY WORDS: MDR-TB; PZA; Central Asia; treatment outcome; drug resistance
A NATIONAL SURVEY IN UZBEKISTAN in 2011 identified multidrug-resistant tuberculosis (MDR-TB; defined as tuberculosis [TB] resistant to at least rifampicin [RMP] and isoniazid [INH], the two main drugs used to treat drug-susceptible TB) in $23 \%$ of new cases and $62 \%$ of retreatment cases. ${ }^{1}$ In Karakalpakstan, a semi-autonomous republic in Uzbekistan, pyrazinamide (PZA) resistance has been reported in $63 \%$ of MDR-TB cases. ${ }^{2}$ A recent metaanalysis estimated that $61 \%$ of patients with MDRTB worldwide had PZA resistance, which equates to 270000 cases annually. ${ }^{3}$

The World Health Organization (WHO) recommendation is to include PZA in an MDR-TB regimen unless evidence of resistance exists. ${ }^{4}$ PZA acts predominantly as a sterilising agent on semi-dormant mycobacteria, ${ }^{5}$ and reduces the required treatment duration in drug-susceptible TB. ${ }^{6}$ The main therapeutic effect in drug-susceptible TB occurs during the first 2 months of treatment, ${ }^{6}$ but whether the same is applicable for MDR-TB is not known. ${ }^{4,6-8}$ PZA has shown synergistic effects with other anti-tuberculosis drugs, ${ }^{9-11}$ which has resulted in its retention in the shorter WHO-recommended MDR-TB regimen, as well as in several novel regimens under evaluation. ${ }^{4,12-15}$ Difficulties exist with PZA drug susceptibility testing (DST) using the standard phenotypic method of the BACTEC ${ }^{\mathrm{TM}}$ MGIT $^{\mathrm{TM}}$ (Mycobacteria Growth Indicator Tube) 960 System, as reports have often shown uncertain reproducibility and reliability, with testing prone to false resistance results. ${ }^{16-18}$

A major factor influencing the WHO recommendation is a recent meta-analysis showing an association between successful outcomes and PZA susceptibility among MDR-TB patients treated with PZA-containing regimens. ${ }^{19}$ Three small primary studies that assessed the association of PZA resistance with treatment outcomes showed conflicting results. ${ }^{20-22}$ No larger primary study is available, and routine PZA DST was not an inclusion criterion in the meta-analysis. ${ }^{19}$

The primary aim of the present study was to assess

Correspondence to: Johanna Kuhlin, London School of Hygiene \& Tropical Medicine, Keppel St, Bloomsbury, London WC1E 7HT, UK. e-mail: johanna.kuhlin@hotmail.com

Article submitted 15 July 2017. Final version accepted 18 December 2017. 
the effect of PZA susceptibility on treatment outcome among MDR-TB patients treated with an intensivephase regimen containing PZA within the drugresistant TB (DR-TB) programme in Karakalpakstan, Uzbekistan. We hypothesised that treatment outcomes would be better in PZA-susceptible than PZAresistant disease. We further assessed the effect of PZA treatment duration on outcomes among patients with PZA strains of unknown resistance or PZAresistant strains.

\section{STUDY POPULATION AND METHODS}

\section{Drug-resistant tuberculosis programme in} Karakalpakstan

Médecins Sans Frontières (MSF) and the Ministry of Health, Uzbekistan, have been collaborating since 2003 to provide treatment for DR-TB in Karakalpakstan. Three phases, beginning in 2003, 2009 and 2012, reflect changing treatment protocols. ${ }^{23-25}$ DST for all drugs was performed initially at the Supranational Reference Laboratory in Borstel, Germany, and later in Karakalpakstan (Appendix Table A.1*). PZA was routinely included in MDR-TB regimens, but could be stopped according to the prevailing treatment protocol at any time if PZA DST showed resistance when the results became available (under the 2003 and 2009 programmes), or after the intensive phase in PZA-resistant patients (under the 2012 programme). Data were continuously collected in an electronic database Epilnfo $^{\mathrm{TM}}$; Centers for Disease Control and Prevention, Atlanta, GA, USA and Excel ${ }^{\circledR}$ 2013; MicroSoft, Redmond, WA, USA).

\section{Study population}

Patients with records in the databases from 2003 to March 2016 were screened using three inclusion criteria: anti-tuberculosis treatment initiated between October 2003 and September 2013; microbiologically confirmed diagnosis of pulmonary MDR-TB using phenotypic DST; and documented treatment outcome. Inclusion was censored in September 2013 to allow for 30 months of treatment. A diagnostic sputum sample was defined as a sample submitted before treatment started or up to 7 days later. Exclusion criteria were as follows: no outcome defined based on the WHO 2013 reporting framework; 26 outcome 'not evaluated' according to the 2013 reporting framework; never having started an MDR-TB regimen based on WHO 2016 guidelines; ${ }^{4}$ human immunodeficiency virus (HIV) positivity; and microbiologically confirmed extensively drug-resistant TB (XDR-TB).

\footnotetext{
* The appendix is available in the online version of this article, at http://www.ingentaconnect.com/content/iuatld/ijtld/2018/ 00000022/00000005/art00014
}

\section{Definitions}

We calculated the number of (non-PZA) drugs to which the strain was resistant at diagnosis as the sum of resistance to INH, RMP, ethambutol (EMB), streptomycin (SM), ofloxacin (OFX), kanamycin (KM) and capreomycin (CPM). If DST results against a drug were unavailable, the strain was assumed to have unknown resistance to the drug in question. Patients with MDR-TB strains were either known to be susceptible or had unknown DST results against the second-line drugs (SLDs) OFX, KM and CPM. Pre-XDR-TB strains had confirmed resistance to either OFX or both KM and CPM. XDR-TB strains had confirmed resistance to OFX and at least one of KM and CPM.

Potentially effective drugs, excluding PZA, were each counted as 1 if DST showed susceptibility or was not performed (see Appendix). Acquired resistance from follow-up DST was taken into account in the monthly calculations; the median in the intensive phase was also estimated. DST for RMP, INH, EMB, OFX, KM, CPM, and SM was included. DST for ethionamide, para-aminosalicylic acid and cycloserine was not considered due to reports of unreliable results; ${ }^{27}$ universal susceptibility to these agents was an inherent assumption. OFX-resistant specimens were also considered resistant to levofloxacin and moxifloxacin (MFX), as neither of these were tested. KM-resistant specimens were considered CPM-susceptible if CPM DST showed susceptibility or was unknown, and vice versa. We calculated PZA treatment through days of prescribed PZA.

We defined PZA treatment as a full PZA-containing intensive phase as PZA treatment on $\geqslant 80 \%$ of days during the intensive phase, a partial PZA regimen as $\angle 80 \%$ of days in the intensive phase, an incomplete PZA regimen as $\geqslant 16 \%$ but $<80 \%$ of days in the intensive phase, and no PZA treatment as $<16 \%$ of days in the intensive phase (equivalent to $<30$ days in a 6-month intensive phase). All outcomes were based on the WHO 2013 definitions. ${ }^{26}$ A 6month cut-off was used until the outcome 'failure due to culture conversion and culture reversion' could be declared, as this was the defined intensive phase; 'failure due to acquired resistance' could be declared at any time. ${ }^{26}$ 'Death' and 'loss to follow-up (LTFU)' were defined according to programme decisions, unless a patient had been defined as 'failure' earlier during treatment.

\section{Data management and analysis}

We used a retrospective cohort study design and multivariable logistic regression. The primary analysis in patients receiving a full PZA-containing intensive phase with known PZA DST results was used to calculate the odds ratio (OR) of a successful outcome (cure or treatment completed) for PZA 
susceptibility compared with resistance. A successful outcome was compared with unsuccessful outcomes (failure or death). We decided a priori to include the variables sex, age, previous use of first-line drugs (FLDs) RMP, INH, EMB, PZA and SM, and presence of cavities on chest X-ray, which are commonly associated with treatment outcome and are adjusted for in other studies. ${ }^{19,22,28}$ We also included year of treatment initiation to account for unmeasured timedependent effects. The secondary analysis assessed the association between successful outcome and duration of PZA treatment, first among patients without diagnostic PZA DST results and then among patients with PZA resistance. We restricted the analysis to patients with no PZA DST results to reduce bias, ${ }^{29}$ as a PZA DST result could guide clinical decisions. The same analyses could not be performed in patients with PZA susceptibility at diagnosis due to low numbers.

In the descriptive analysis, we used the $\chi^{2}$ test for statistical testing for categorical variables and the Wilcoxon rank-sum test for continuous variables. We used the Wald test in the crude and multivariable models, and the likelihood ratio test to assess interaction in the final multivariable logistic models. Missing values were included as unknown if $>10 \%$ were missing, but were otherwise coded as missing. Data cleaning and analysis were performed using STATA v14.1 (Stata Corporation, College Station, TX, USA).

Power calculations for the main analysis using the available patient cohort $(n=508$, outcomes ratio 3.5 [successful 396; death/failure 112], baseline proportion of success $78 \%$ ) used an OR of 1.6 for successful outcome in PZA-susceptible compared with PZAresistant MDR-TB based on a meta-analysis, ${ }^{19}$ with a two-sided likelihood ratio test and $\alpha=0.05$, yielding a power of $40 \%$.

Sensitivity analyses were undertaken for the primary analysis in patients with only bacteriologically confirmed $\mathrm{TB}$, receiving $\geqslant 6$ months of treatment, and only under the 2012 programme. An additional model compared treatment success with death/failure/LTFU.

The study fulfilled the exemption criteria of the MSF Ethics Review Board (ERB) for a posteriori analyses of routinely collected clinical data, and did not require MSF ERB review. ${ }^{30}$ The study was conducted with permission from Dr S Wong (Medical Director, MSF, Operational Centre Amsterdam, The Netherlands). The study protocol was also approved by the London School of Hygiene \& Tropical Medicine Research Ethics Committee, London, UK.

\section{RESULTS}

\section{Patient characteristics}

Of a total of 2593 patients, 2446 (94.3\%) were included, $832(34.0 \%)$ of whom had a diagnostic
PZA DST result available (Appendix Figure). Table 1 shows the characteristics of the 2446 patients included. The median treatment duration was 20 months (range 0-38), and the median duration of PZA treatment was 12 months (range 0-34). Isolates were resistant to a median of four drugs at diagnosis (interquartile range 4-4);87.2\% ( $n=$ 2132) of the intensive phase regimens contained at least five effective drugs. A successful outcome was recorded in $59.4 \%$ of patients, $5.8 \%$ died, $11.9 \%$ failed treatment and $22.9 \%$ were lost to follow-up. A full PZA regimen was prescribed in $90.1 \%$ (1450/ $1610)$ of patients with no available PZA DST result, $90.8 \%(197 / 217)$ of those with PZA-susceptible strains and $76.6 \%(469 / 612)$ of those with PZAresistant strains (seven patients were excluded as they had received PZA treatment only in the continuation phase). Of patients with available PZA DST results at diagnosis, 73.6\% (612/832) had PZA-resistant strains.

\section{Main results}

In the primary unadjusted analysis (Table 2), we found no evidence of an association between a successful outcome and PZA susceptibility among patients receiving a full PZA-containing intensive phase (odds ratio [OR] 1.04, 95\% confidence interval [CI] $0.65-1.65, P=0.9)$. Patients with previous use of FLDs (OR 0.54, 95\% CI 0.31-0.93, $P=0.03$ ) and SLDs (OR 0.55 , 95\% CI $0.32-0.95, P=0.03$ ) had approximately $45 \%$ lower odds of success. The odds of a successful outcome decreased with increasing numbers of drugs to which the strain was resistant at diagnosis (OR 0.64, 95\% CI 0.51-0.81 per resistant drug, $P<0.001$ ).

In the multivariable analysis (Table 2), there was also no evidence of an association between a successful outcome and PZA susceptibility (OR $0.86,95 \%$ CI $0.51-1.44, P=0.6)$, after adjustment for sex, age, previous FLD use, cavities on chest X-ray at diagnosis, programme year and number of drugs to which the diagnostic strain was resistant. We found no clinically important interaction variables in the final model. Sputum smear and previous use of SLDs did not change the OR by more than $10 \%$ in the multivariable model, and were not included in the final analysis. The model comparing success with death/failure/LTFU had comparable results (Appendix Table A.2). Similar results were seen in the three sensitivity analyses (Appendix Tables A.3-A.5).

The secondary adjusted multivariable analyses showed no evidence of an association between successful outcome and a full PZA-containing intensive phase, either in patients with no available baseline PZA DST results at diagnosis (OR 0.86, 95\% CI 0.49-1.51, $P=0.6$; Appendix Table A.6) or in patients with PZA-resistant MDR-TB strains (OR 1.38, 95\% CI 0.71-2.68, $P=0.3$; Appendix Table 
Table 1 Demographic and clinical characteristics of MDR-TB patients with and without a PZA DST result available and PZA-resistant and PZA-susceptible patients

\begin{tabular}{|c|c|c|c|c|c|c|c|}
\hline & $\begin{array}{c}\text { All included } \\
\text { patients } \\
(n=2446,100 \%) \\
n(\%)\end{array}$ & $\begin{array}{c}\text { PZA DST result } \\
\text { not available } \\
(1614 / 2446,66.0) \\
n(\%)\end{array}$ & $\begin{array}{c}\text { PZA DST result } \\
\text { available } \\
(832 / 2446,34.0) \\
n(\%)\end{array}$ & $P$ value* & $\begin{array}{c}\text { PZA-resistant } \\
(612 / 832,73.6) \\
n(\%)\end{array}$ & $\begin{array}{c}\text { PZA-susceptible } \\
(220 / 832,26.4) \\
n(\%)\end{array}$ & $P$ value* \\
\hline \multicolumn{8}{|l|}{ Sex } \\
\hline Female & $1257(51.4)$ & $834(51.7)$ & $423(50.8)$ & & $318(52.0)$ & $105(47.7)$ & \\
\hline Male & 1189 (48.6) & $780(48.3)$ & $409(49.2)$ & 0.7 & $294(48.0)$ & $115(52.3)$ & 0.3 \\
\hline $\begin{array}{l}\text { Age, years, } \\
\text { median [IQR] }\end{array}$ & 30.5 [24-42] & 30 [24-41] & 31 [24-42] & 0.2 & 31 [24-42] & 32 [25-41.5] & 0.3 \\
\hline \multicolumn{8}{|l|}{ Marital status } \\
\hline Not married & $1046(42.8)$ & $694(43.0)$ & $352(42.3)$ & & $260(42.5)$ & $92(41.8)$ & \\
\hline Married & $1400(57.2)$ & $920(57.0)$ & $480(57.7)$ & 0.7 & $352(57.5)$ & $128(58.2)$ & 0.9 \\
\hline \multicolumn{8}{|l|}{ Employment status } \\
\hline Other ${ }^{\dagger}$ & 1099 (44.9) & $714(44.2)$ & $385(46.3)$ & & $284(46.4)$ & $101(45.9)$ & \\
\hline Unemployed & $1347(55.1)$ & $900(55.8)$ & $447(53.7)$ & 0.3 & $328(53.6)$ & $119(54.1)$ & 0.9 \\
\hline \multicolumn{8}{|l|}{ Body mass index, kg/m² } \\
\hline Normal $(\geqslant 18.5)$ & $1156(47.3)$ & $764(47.3)$ & $392(47.1)$ & & $297(48.5)$ & $95(43.2)$ & \\
\hline Underweight $(<18.5)$ & $1290(52.4)$ & $850(52.7)$ & $440(52.9)$ & 0.9 & $315(51.5)$ & $125(56.8)$ & 0.2 \\
\hline \multicolumn{8}{|l|}{ TB programme } \\
\hline 2003 & $852(34.8)$ & $673(41.7)$ & $179(21.5)$ & & $115(18.8)$ & $64(29.1)$ & \\
\hline 2009 & $844(34.5)$ & $601(37.2)$ & $243(29.2)$ & & 199 (32.5) & $44(20.0)$ & \\
\hline 2012 & $750(30.7)$ & $340(21.1)$ & $410(49.3)$ & $<0.001$ & $298(48.7)$ & $112(50.9)$ & $<0.001$ \\
\hline \multicolumn{8}{|l|}{ Alcohol use $e^{\ddagger}$} \\
\hline No & $2182(89.2)$ & $1437(89.0)$ & $745(89.5)$ & & $551(90.0)$ & $194(88.2)$ & \\
\hline Yes & $264(10.8)$ & $177(11.0)$ & $87(10.5)$ & 0.7 & $61(10.0)$ & $26(11.8)$ & 0.4 \\
\hline \multicolumn{8}{|l|}{ Diabetes } \\
\hline No & $1130(46.2)$ & $527(32.7)$ & $603(72.5)$ & & $455(74.3)$ & $148(67.3)$ & \\
\hline Yes & $105(4.3)$ & $63(3.9)$ & $42(5.0)$ & & $35(5.7)$ & $7(3.2)$ & \\
\hline Unknown & $1211(49.5)$ & $1024(63.4)$ & $187(22.5)$ & $<0.001$ & 122 (19.9) & $65(29.5)$ & 0.007 \\
\hline \multicolumn{8}{|l|}{ Previous first-line drugs } \\
\hline No & 309 (12.6) & $132(8.2)$ & $177(21.3)$ & & $123(20.1)$ & $54(24.5)$ & \\
\hline Yes & $2137(87.4)$ & $1482(91.8)$ & $655(78.7)$ & $<0.001$ & $489(79.9)$ & $166(75.5)$ & 0.2 \\
\hline \multicolumn{8}{|c|}{ Previous second-line drugs } \\
\hline No & $1931(79.1)$ & $1270(78.7)$ & $661(79.4)$ & & 489 (79.9) & $172(78.2)$ & \\
\hline Yes & $515(21.1)$ & $344(21.3)$ & $171(20.6)$ & 0.7 & $123(20.1)$ & $48(21.8)$ & 0.6 \\
\hline \multicolumn{8}{|l|}{ Cavities on X-ray ${ }^{\S}$} \\
\hline No & 419 (18.6) & $223(15.6)$ & $196(23.6)$ & & $142(23.4)$ & $54(24.8)$ & \\
\hline Yes & $1835(81.4)$ & $1206(84.4)$ & $629(75.6)$ & $<0.001$ & $465(76.6)$ & $164(75.2)$ & 0.7 \\
\hline \multicolumn{8}{|l|}{ Sputum smear" } \\
\hline Negative & $491(21.0)$ & $284(18.8)$ & $207(25.1)$ & & $153(25.3)$ & $54(24.7)$ & \\
\hline Scanty/1+ & $691(29.6)$ & $450(29.7)$ & $241(29.2)$ & & $180(29.8)$ & $61(27.9)$ & \\
\hline $2+13+$ & $1155(49.4)$ & $779(51.5)$ & $376(45.6)$ & 0.001 & $272(45.0)$ & $104(47.5)$ & 0.8 \\
\hline \multicolumn{8}{|l|}{ Resistance pattern } \\
\hline MDR-TB & $2054(84.0)$ & $1368(84.8)$ & $780(93.8)$ & & $500(81.7)$ & $186(84.5)$ & \\
\hline Pre-XDR-TB & $392(16.0)$ & $246(15.2)$ & $146(17.5)$ & 0.1 & $112(18.3)$ & $34(15.5)$ & 0.3 \\
\hline $\begin{array}{l}\text { Number of drugs to } \\
\text { which diagnostic } \\
\text { strain is resistant, } \\
\text { median [IQR] }\end{array}$ & $4[4-4]$ & $4[4-4]$ & $4[4-5]$ & 0.003 & $4[4-5]$ & $4[3-4]$ & $<0.001$ \\
\hline \multicolumn{8}{|c|}{ Median potentially effective drugs in the intensive phase ${ }^{\#}$} \\
\hline $2-4$ & $314(12.8)$ & $151(9.4)$ & $163(19.6)$ & & $112(18.3)$ & $51(23.2)$ & \\
\hline $5-6$ & $2029(83.0)$ & $1388(86.0)$ & $641(77.0)$ & & $479(78.3)$ & $162(73.6)$ & \\
\hline $7-8$ & $103(4.2)$ & $75(4.6)$ & $28(3.4)$ & $<0.001$ & $21(3.4)$ & $7(3.2)$ & 0.3 \\
\hline \multicolumn{8}{|l|}{ Outcome } \\
\hline Success & $1453(59.4)$ & $958(59.4)$ & 495 (59.5) & & $362(59.2)$ & $133(60.5)$ & \\
\hline Death & $141(5.8)$ & $80(5.0)$ & $61(7.3)$ & & $47(7.7)$ & $14(6.4)$ & \\
\hline Failure & 291 (11.9) & $196(12.1)$ & 95 (11.4) & & 73 (11.9) & $22(10.0)$ & \\
\hline Loss to follow-up & $561(22.9)$ & $380(23.5)$ & $181(21.8)$ & 0.09 & $130(21.2)$ & $51(23.2)$ & 0.8 \\
\hline
\end{tabular}

* $\chi^{2}$ test for categorical and Wilcoxon rank sum test for continuous variables.

${ }^{+}$Including the following categories: employed, retired, student, housework, disabled.

¥ Self-reported.

§Missing values, $n=192$.

"Missing values, $n=109$

\# Median of monthly number of potentially effective drugs, except PZA, in the intensive phase, with all drugs counted as 1.

MDR-TB = multidrug-resistant TB; PZA = pyrazinamide; $\mathrm{DST}=$ drug susceptibility testing; $I \mathrm{QR}=$ interquartile range; $T B=$ tuberculosis; $X D R=$ extensively drugresistant TB. 
Table 2 Crude and adjusted analyses of the effect of PZA susceptibility and other exposure variables on treatment outcome among patients treated with a full PZA-containing intensive phase

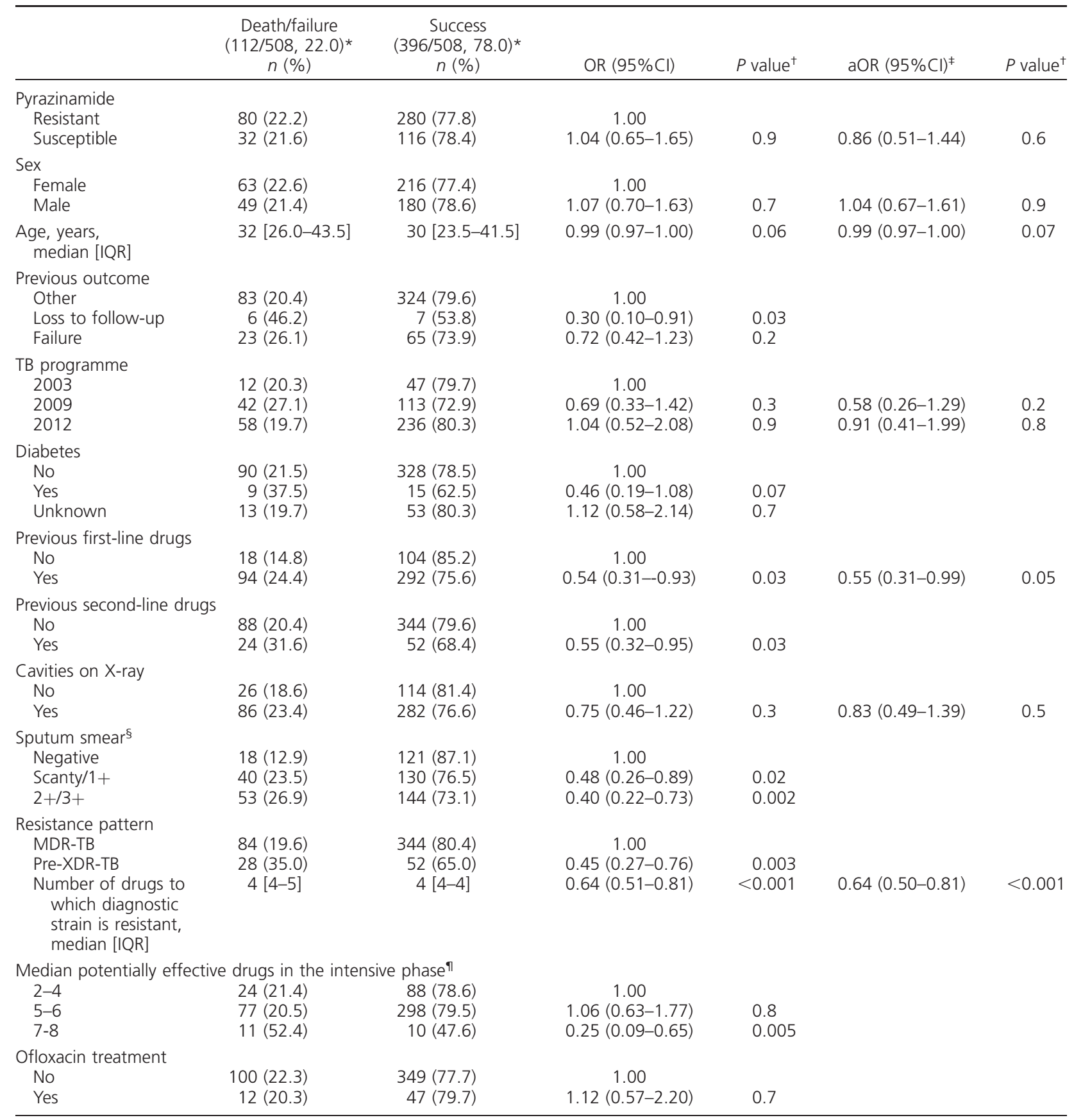

* Of 651 patients with outcome death/failure/cure/treatment completed, 142 excluded due to no PZA treatment in the full intensive phase, one patient excluded due to unknown X-ray result.

${ }^{\dagger}$ Wald test.

* Adjusted for age, sex, previous first-line drugs, cavities on X-ray, programme year and number of drugs to which strain was resistant at diagnosis

$\S$ Two missing values due to unknown smear result.

" Median monthly number of potentially effective drugs, except PZA, in intensive phase, with all drugs counted as 1 .

$\mathrm{PZA}=$ pyrazinamide; $\mathrm{OR}=$ odds ratio; $\mathrm{Cl}=$ confidence interval; $\mathrm{aOR}=$ adjusted $\mathrm{OR}$; IQR = interquartile range; $\mathrm{TB}=$ tuberculosis; $\mathrm{MDR}-\mathrm{TB}=$ multidrug-resistant $\mathrm{TB}$; $\mathrm{XDR}-\mathrm{TB}=$ extensively drug-resistant TB

A.6). Results were similar for patients who were treated with an incomplete PZA regimen or a full PZA-containing intensive phase compared with no PZA treatment among those with no PZA DST result and those with PZA-resistant MDR-TB strains. The same analyses using the death/failure/LTFU model had comparable results (Appendix Table A.7).

\section{DISCUSSION}

This is the largest single-site study to assess the impact of PZA resistance and treatment duration on treatment outcome in patients with MDR-TB. We found no evidence of an association between a successful outcome and PZA susceptibility among MDR-TB 
patients treated with a standard full PZA-containing intensive phase of a WHO-recommended regimen in a high MDR-TB burden setting. There was no evidence of an association between a successful outcome and PZA treatment duration in the intensive phase.

The main result was unexpected, and did not support our hypothesis that a treatment regimen with a full PZA-containing intensive phase would improve treatment outcomes in patients with PZA-susceptible strains compared with PZA-resistant strains. Our results are therefore consistent with two smaller previous primary studies, ${ }^{20,21}$ but not with the metaanalysis and another small primary study from Peru. ${ }^{19,31}$

Several explanations could be postulated. Even with the inclusion of all eligible patients for more than one decade, the sample size had low power for the main analysis. The retrospective and observational nature of the study contributed to an increased risk of bias. Prescription of a full PZA-containing intensive phase could also have been influenced by PZA DST results or other associated baseline characteristics, resulting in selection bias, although clear protocols were in use to routinely include PZA in MDR-TB regimens.

The main effect of PZA may be its contribution to shortening the duration of treatment, ${ }^{32,33}$ rather than improving the outcome of an already lengthy regimen. This would also support the improved result of the shortened treatment regimen now recommended by the WHO that includes PZA. ${ }^{4}$ Patients might also have had sufficient likely effective drugs in their regimen $(87.2 \%$ had five or more likely effective drugs in the intensive phase; Table 1), rendering additional PZA redundant. ${ }^{22}$

The secondary analysis also showed insufficient evidence of an association between a successful outcome and a full PZA-containing intensive phase among patients with unknown PZA DST results and those with PZA-resistant MDR-TB strains. A possible explanation in the former could be the high background PZA resistance in MDR-TB patients in Karakalpakstan (73.6\%; Table 1). Optimal PZA treatment duration in MDR-TB may be longer than the 2 months used for drug-susceptible $\mathrm{TB}^{6}$ due to the lower efficacy of SLDs. This effect could be limited to patients with PZA-susceptible MDR-TB strains, but PZA-resistant strains might also benefit, due to a synergistic effect with other drugs. ${ }^{34}$ We did not find that a different duration of PZA treatment in the intensive phase was associated with greater odds of a successful outcome, although some numbers were small (Appendix Table A.6).

The generalisability of this study would be limited to settings with low HIV prevalence and high background prevalence of SLD resistance, as in other former Soviet Union countries. Caution is needed when extrapolating the results to other settings, as background resistance patterns might be expected to change the impact of PZA treatment. Furthermore, these results refer to a background standard MDR-TB regimen, but might not be applicable to newer regimens.

The main limitation of our study was the low power for the main analysis and the risk of bias due to the observational study design. Although we used both restriction and stratification, bias cannot be accounted for in the analysis. Patients were included over a long time, and unmeasured factors could lead to residual confounding, although we adjusted for programme year. Another limitation was the determination of PZA susceptibility using MGIT, with possible false resistance, which could have affected the results. Furthermore, adjustment was made for initial PZA DST results, but not for acquired PZA resistance during treatment. Another limitation was the way in which potentially effective drugs were all counted as 1 ; we were unable to justify the assignment of differential weights.

Nevertheless, because this was the first large primary study with these findings, with all the associated limitations of a retrospective observational cohort, cautious consideration should be made before changing treatment protocols. A clinical trial assessing the effect of PZA inclusion and treatment duration could address this question, but might not be regarded as a priority in the current arena. An updated meta-analysis including this full cohort would be worthwhile.

\section{CONCLUSIONS}

The present study provided provocative but insufficient evidence to warrant changing PZA treatment protocols, although the evidence relating to PZA for the WHO 2016 guidelines was weak. Until further evidence supporting these findings emerges, it seems prudent to continue including PZA in standard MDR-TB regimens unless resistance is certain.

\section{Acknowledgement}

The authors thank all the staff, both within Médecins Sans Frontières and at the Ministry of Health in Karakalpakstan, Uzbekistan, who treated and cared for patients, worked in the laboratory, and collected data, which all formed part of our study. This project is dedicated to all MDR-TB patients in Karakalpakstan who made this study possible, and to those who continue to struggle with dreadful treatment of a curable disease.

Conflicts of interest: none declared.

\section{References}

1 Ulmasova D J, Uzakova G, Tillyashayhov $\mathrm{M} \mathrm{N}$, et al. Multidrug-resistant tuberculosis in Uzbekistan: results of a nationwide survey, 2010 to 2011. Euro Surveill 2013; 18: 20609. 
2 Lalor M, Allamuratova S, Tiegay Z, et al, editors. Treatment outcomes in multidrug-resistant TB patients in Uzbekistan. $42^{\text {nd }}$ Union World Conference on Lung Health, 26-30 October 2011, Lille, France. Int J Tuberc Lung Dis 2011; 15 (Suppl 3): S232. [Abstract no PC-920-29]

3 Whitfield M G, Soeters H M, Warren R M, et al. A global perspective on pyrazinamide resistance: systematic review and meta-analysis. PLOS ONE 2015; 10: e0133869.

4 World Health Organization. WHO treatment guidelines for drug-resistant tuberculosis: 2016 update. WHO/HTM/TB/ 2016.04. Geneva, Switzerland: WHO, 2016.

5 Mitchison D A. The action of anti-tuberculosis drugs in shortcourse chemotherapy. Tubercle 1985; 66: 219-225.

6 Fox W, Ellard G A, Mitchison D A. Studies on the treatment of tuberculosis undertaken by the British Medical Research Council tuberculosis units, 1946-1986, with relevant subsequent publications. Int J Tuberc Lung Dis 1999; 3 (Suppl 2): S231-S279.

7 Donald P R, Diacon A H. The early bactericidal activity of antituberculosis drugs: a literature review. Tuberculosis 2008; 88 (Suppl 1): S75-S83.

8 Lakshminarayana S B, Huat T B, Ho P C, et al. Comprehensive physicochemical, pharmacokinetic and activity profiling of anti-TB agents. J Antimicrob Chemother 2015; 70: 857-867.

9 East African/British Medical Research Council. Controlled clinical trial of four short-course regimens of chemotherapy for two durations in the treatment of pulmonary tuberculosis. Second report. Third East African/British Medical Research Council Study. Tubercle 1980; 61: 59-69.

10 Ibrahim M, Andries K, Lounis N, et al. Synergistic activity of R207910 combined with pyrazinamide against murine tuberculosis. Antimicrob Agents Chemother 2007; 51: 10111015.

11 Tasneen R, Tyagi S, Williams K, Grosset J, Nuermberger E. Enhanced bactericidal activity of rifampin and/or pyrazinamide when combined with PA-824 in a murine model of tuberculosis. Antimicrob Agents Chemother 2008; 52: 3664-3668.

12 Van Deun A, Maug A K, Salim M A, et al. Short, highly effective, and inexpensive standardized treatment of multidrugresistant tuberculosis. Am J Respir Crit Care Med 2010; 182: 684-692.

13 Nuermberger E, Tyagi S, Tasneen R, et al. Powerful bactericidal and sterilizing activity of a regimen containing PA-824, moxifloxacin, and pyrazinamide in a murine model of tuberculosis. Antimicrob Agents Chemother 2008; 52: 15221524.

14 Dawson R, Diacon A H, Everitt D, et al. Efficiency and safety of the combination of moxifloxacin, pretomanid (PA-824), and pyrazinamide during the first 8 weeks of anti-tuberculosis treatment: a Phase 2 b, open-label, partly randomised trial in patients with drug-susceptible or drug-resistant pulmonary tuberculosis. Lancet 2015; 385: 1738-17347.

15 Diacon A H, Dawson R, von Groote-Bidlingmaier F, et al. Bactericidal activity of pyrazinamide and clofazimine alone and in combinations with pretomanid and bedaquiline. Am J Respir Crit Care Med 2015; 191: 943-953.

16 Chedore P, Bertucci L, Wolfe J, Sharma M, Jamieson F. Potential for erroneous results indicating resistance when using the BACTEC ${ }^{\mathrm{TM}}$ MGIT $^{\mathrm{TM}} 960$ system for testing susceptibility of Mycobacterium tuberculosis to pyrazinamide. J Clin Microbiol 2010; 48: 300-301.

17 Kontos F, Nicolaou S, Kostopoulos C, et al. Multicenter evaluation of the fully automated BACTEC ${ }^{\mathrm{TM}}$ MGIT $^{\mathrm{TM}} 960$ system for susceptibility testing of Mycobacterium tuberculosis to pyrazinamide: comparison with the radiometric BACTEC 460TB system. J Microbiol Methods 2003; 55: 331-333.
18 Zhang Y, Permar S, Sun Z. Conditions that may affect the results of susceptibility testing of Mycobacterium tuberculosis to pyrazinamide. J Med Microbiol 2002; 51: 42-49.

19 Bastos M L, Hussain H, Weyer K, et al. Treatment outcomes of patients with multidrug-resistant and extensively drug-resistant tuberculosis according to drug susceptibility testing to first- and second-line drugs: an individual patient data meta-analysis. Clin Infect Dis 2014; 59: 1364-1374.

20 Chang K C, Leung C C, Yew W W, et al. Pyrazinamide may improve fluoroquinolone-based treatment of multidrugresistant tuberculosis. Antimicrob Agents Chemother 2012; 56: 5465-5475.

21 Budzik J M, Jarlsberg L G, Higashi J, et al. Pyrazinamide resistance, Mycobacterium tuberculosis lineage and treatment outcomes in San Francisco, California. PLOS ONE 2014; 9: e95645.

22 Yuen C M, Kurbatova E V, Tupasi T, et al. Association between regimen composition and treatment response in patients with multidrug-resistant tuberculosis: a prospective cohort study. PLOS Med 2015; 12: e1001932.

23 Ministry of Health of Uzbekistan, Ministry of Health of Karakalpakstan, Médecins Sans Frontières-Operation Centre Amsterdam (MSF-OCP). Clinical manual for treatment of resistant tuberculosis. Karakalpakstan, Uzbekistan: $\mathrm{MoH}$ Uzbekistan, MoH Karakalpakstan, MSF-OCP, 2009.

24 Ministry of Health of Uzbekistan, Ministry of Health of Karakalpakstan, Médecins Sans Frontières-Operation Centre Amsterdam (MSF-OCP). Clinical guidelines on comprehensive TB treatment for drug-sensitive and drug-resistant TB: Protocol. Karakalpakstan, Uzbekistan: MoH Uzbekistan, MoH Karakalpakstan, MSF-OCP, 2012.

25 Cox H S, Kalon S, Allamuratova S, et al. Multidrug-resistant tuberculosis treatment outcomes in Karakalpakstan, Uzbekistan: treatment complexity and XDR-TB among treatment failures. PLOS ONE 2007; 2: e1126.

26 World Health Organisation. Definitions and reporting framework for tuberculosis -2013 revision. WHO/HTM/TB/ 2013.2. Geneva, Switzerland: WHO, 2013.

27 Kim S J. Drug-susceptibility testing in tuberculosis: methods and reliability of results. Eur Respir J 2005; 25: 564-569.

28 Ahuja S D, Ashkin D, Avendano M, et al. Multidrug resistant pulmonary tuberculosis treatment regimens and patient outcomes: an individual patient data meta-analysis of 9,153 patients. PLOS Med 2012; 9: e1001300.

29 Psaty B M, Siscovick D S. Minimizing bias due to confounding by indication in comparative effectiveness research: the importance of restriction. JAMA 2010; 304: 897-898.

30 Médecins Sans Frontières Ethics Review Board. Médecins Sans Frontières Research Ethics Framework: guidance document. London, UK: MSF, 2013.

31 Mitnick C, Bayona J, Palacios E, et al. Community-based therapy for multidrug-resistant tuberculosis in Lima, Peru. N Engl J Med 2003; 348: 119-128.

32 Lange C, Abubakar I, Alffenaar J W, et al. Management of patients with multidrug-resistant/extensively drug-resistant tuberculosis in Europe: a TBNET consensus statement. Eur Respir J 2014; 44: 23-63.

33 Shi W, Zhang X, Jiang X, et al. Pyrazinamide inhibits transtranslation in Mycobacterium tuberculosis: a potential mechanism for shortening the duration of tuberculosis chemotherapy. Science 2011; 333: 1630-1632.

34 Franke M F, Becerra M C, Tierney D B, et al. Counting pyrazinamide in regimens for multidrug-resistant tuberculosis. Ann Am Thorac Soc 2015; 12: 674-679. 


\section{APPENDIX}

Drug groups for the treatment of multidrug-resistant tuberculosis according to World Health Organization 2016 guidelines. $^{26}$

Group A: Levofloxacin, moxifloxacin, gatifloxacin Group B: Amikacin, kanamycin, capreomycin (streptomycin)
Group C: Ethionamide/prothionamide, cycloserine/ terizidone, linezolid, clofazimine

Group D:

D1: Pyrazinamide, ethambutol, high-dose isoniazid

D2: Bedaquiline, delamanid

D3: Para-aminosalicylic acid, imipenem-cilastin, meropenem, amoxicillin-clavulanate, thioacetazone.

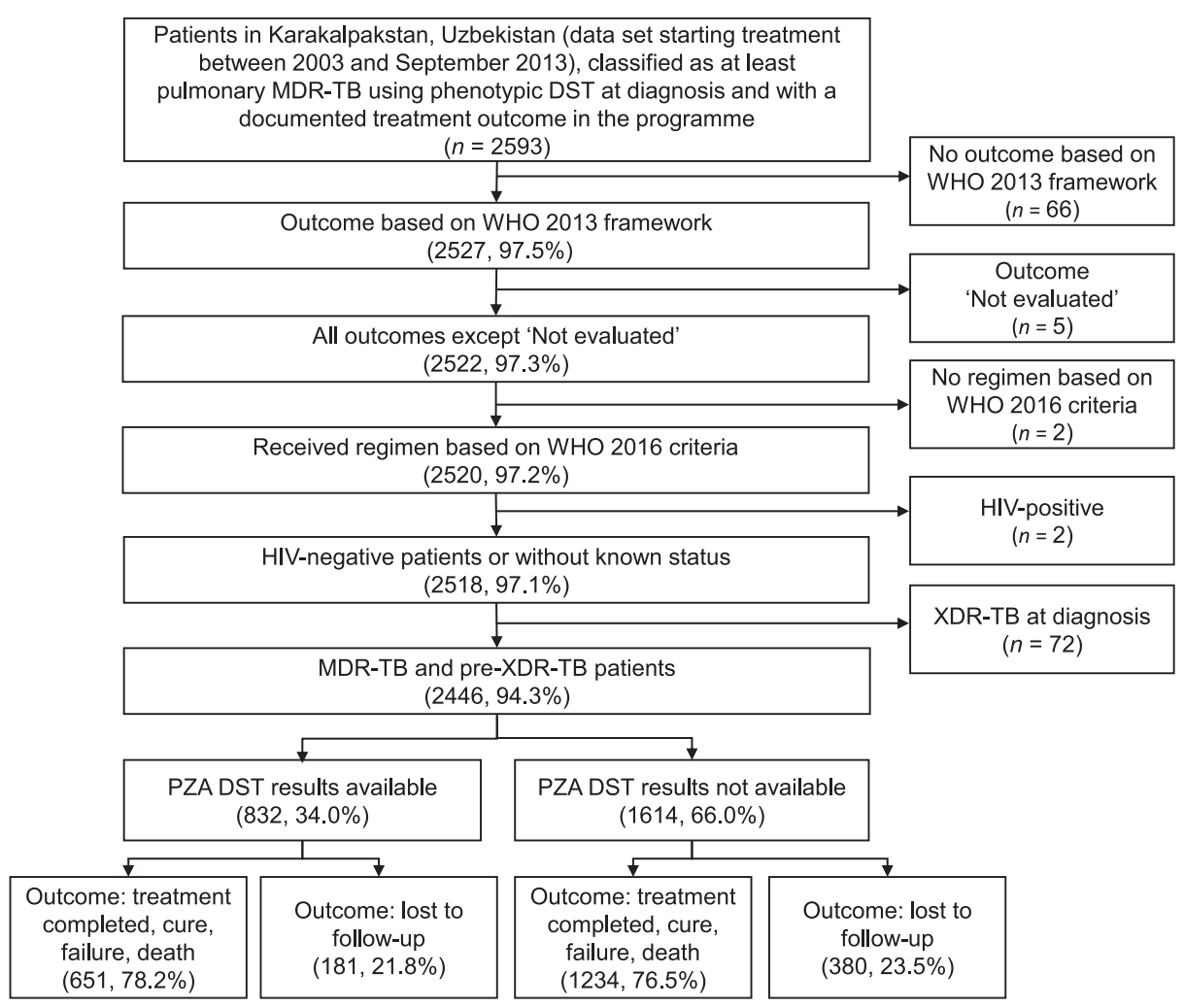

Figure Flow diagram of the inclusion and exclusion criteria of patients from the DR-TB treatment programme in Karakalpakstan, Uzbekistan. MDR-TB = multidrug-resistant tuberculosis; DST = drug susceptibility testing; $\mathrm{WHO}=$ World Health Organization; HIV = human immunodeficiency virus; $\mathrm{XDR}-\mathrm{TB}=$ extensively drug-resistant tuberculosis; $\mathrm{PZA}=$ pyrazinamide.

Table A.1 Methods and location of DST used by the DR-TB programme in Karakalpakstan, Uzbekistan

\begin{tabular}{|c|c|c|}
\hline DST method & $\begin{array}{c}\text { Supranational } \\
\text { Reference Laboratory, } \\
\text { Borstel, Germany }\end{array}$ & Laboratory in Karakalpakstan \\
\hline \multicolumn{3}{|c|}{ Culture-based DST, except PZA } \\
\hline MGIT* & 2003-2007 & 2007 onwards \\
\hline Löwenstein-Jensen ${ }^{\dagger}$ & NA & 2003 onwards \\
\hline \multicolumn{3}{|l|}{ PZA DST method } \\
\hline MGIT* & $\begin{array}{l}\text { Routinely conducted } \\
\text { between 2003-2006 }\end{array}$ & $\begin{array}{l}\text { Started November 2010, routinely } \\
\text { conducted from } 2012 \text { onwards }\end{array}$ \\
\hline
\end{tabular}


Table A.2 Crude and adjusted analyses of the effect of PZA susceptibility and other exposure variables on treatment outcome among patients treated with a regimen with PZA throughout the intensive phase: death/failure/LTFU model

\begin{tabular}{|c|c|c|c|c|c|c|}
\hline & $\begin{array}{c}\text { Death/failure/LTFU } \\
n(\%)\end{array}$ & $\begin{array}{l}\text { Success } \\
n(\%)\end{array}$ & OR $(95 \% \mathrm{Cl})$ & $P$ value* & $\mathrm{aOR}(95 \% \mathrm{Cl})^{\dagger}$ & $P$ value* \\
\hline $\begin{array}{l}\text { Pyrazinamide } \\
\text { Resistant } \\
\text { Susceptible }\end{array}$ & $\begin{array}{r}267 / 663 *(40.3) \\
188(40.2) \\
79(40.5)\end{array}$ & $\begin{array}{r}396 / 663 *(59.7) \\
280(59.8) \\
116(59.5)\end{array}$ & $\begin{array}{c}1.00 \\
0.99(0.70-1.39)\end{array}$ & 0.9 & $0.80(0.56-1.17)$ & 0.3 \\
\hline $\begin{array}{l}\text { Sex } \\
\text { Female } \\
\text { Male }\end{array}$ & $\begin{array}{l}121(35.9) \\
146(44.8)\end{array}$ & $\begin{array}{l}216(64.1) \\
180(55.2)\end{array}$ & $\begin{array}{c}1.00 \\
0.69(0.51-0.94)\end{array}$ & 0.02 & $0.67(0.49-0.93)$ & 0.02 \\
\hline $\begin{array}{l}\text { Age, years, } \\
\text { median }[\mathrm{IQR}]\end{array}$ & 32 [25-43] & 30 [23.5-41.5] & $0.99(0.98-1.00)$ & 0.05 & $0.99(0.98-1.00)$ & 0.08 \\
\hline $\begin{array}{l}\text { Previous outcome } \\
\text { Other } \\
\text { LTFU } \\
\text { Failure }\end{array}$ & $\begin{array}{r}206(38.9) \\
13(65.0) \\
48(42.5)\end{array}$ & $\begin{array}{r}324(61.1) \\
7(35.0) \\
65(57.5)\end{array}$ & $\begin{array}{c}1.00 \\
0.34(0.13-0.87) \\
0.86(0.57-1.30)\end{array}$ & $\begin{array}{l}0.03 \\
0.5\end{array}$ & & \\
\hline $\begin{array}{l}\text { TB programme } \\
2003 \\
2009 \\
2012\end{array}$ & $\begin{array}{r}21(30.9) \\
99(46.7) \\
147(38.4)\end{array}$ & $\begin{array}{r}47(69.1) \\
113(53.3) \\
236(61.6)\end{array}$ & $\begin{array}{c}1.00 \\
0.51(0.29-0.91) \\
0.72(0.41-1.25)\end{array}$ & $\begin{array}{l}0.02 \\
0.3\end{array}$ & $\begin{array}{l}0.42(0.22-0.79) \\
0.61(0.33-1.13)\end{array}$ & $\begin{array}{l}0.007 \\
0.1\end{array}$ \\
\hline $\begin{array}{l}\text { Diabetes } \\
\text { No } \\
\text { Yes } \\
\text { Unknown }\end{array}$ & $\begin{array}{r}223(40.5) \\
22(59.5) \\
22(29.3)\end{array}$ & $\begin{array}{r}328(59.5) \\
15(40.5) \\
53(70.7)\end{array}$ & $\begin{array}{c}1.00 \\
0.46(0.24-0.91) \\
1.12(0.58-2.14)\end{array}$ & $\begin{array}{l}0.03 \\
0.07\end{array}$ & & \\
\hline $\begin{array}{l}\text { Previous first-line drugs } \\
\text { No } \\
\text { Yes }\end{array}$ & $\begin{array}{r}61(37.0) \\
206(41.4)\end{array}$ & $\begin{array}{l}104(63.0) \\
292(58.6)\end{array}$ & $\begin{array}{c}1.00 \\
0.83(0.58-1.20)\end{array}$ & 0.3 & $0.83(0.57-1.22)$ & 0.3 \\
\hline $\begin{array}{l}\text { Previous second-line } d r \\
\text { No } \\
\text { Yes }\end{array}$ & $\begin{array}{r}227(39.8) \\
40(43.5)\end{array}$ & $\begin{array}{r}344(60.2) \\
52(56.5)\end{array}$ & $\begin{array}{c}1.00 \\
0.86(0.55-1.34)\end{array}$ & 0.5 & & \\
\hline $\begin{array}{l}\text { Cavities on X-ray } \\
\text { No } \\
\text { Yes }\end{array}$ & $\begin{array}{r}65(36.3) \\
202(41.7)\end{array}$ & $\begin{array}{l}114(63.7) \\
282(58.3)\end{array}$ & $\begin{array}{c}1.00 \\
0.80(0.56-1.13)\end{array}$ & 0.2 & $0.81(0.56-1.18)$ & 0.3 \\
\hline $\begin{array}{l}\text { Sputum smear }{ }^{\ddagger} \\
\text { Negative } \\
\text { Scanty/1+ } \\
2+/ 3+\end{array}$ & $\begin{array}{r}66(35.3) \\
86(39.8) \\
114(44.2)\end{array}$ & $\begin{array}{l}121(64.7) \\
130(60.2) \\
144(55.8)\end{array}$ & $\begin{array}{c}1.00 \\
0.82(0.55-1.24) \\
0.69(0.47-1.02)\end{array}$ & $\begin{array}{l}0.4 \\
0.06\end{array}$ & & \\
\hline $\begin{array}{l}\text { Resistance pattern } \\
\text { MDR-TB } \\
\text { Pre-XDR-TB } \\
\text { Number of drugs to } \\
\text { which diagnostic } \\
\text { strain is resistant, } \\
\text { median [IQR] }\end{array}$ & $\begin{array}{c}217(38.7) \\
50(49.0) \\
4[4-5]\end{array}$ & $\begin{array}{c}344(61.3) \\
52(51.0) \\
4[4-4]\end{array}$ & $\begin{array}{c}1.00 \\
0.66(0.43-1.00) \\
0.76(0.63-0.91)\end{array}$ & $\begin{array}{l}0.05 \\
0.002\end{array}$ & $0.74(0.62-0.89)$ & 0.002 \\
\hline $\begin{array}{l}\text { Median potentially effe } \\
2-4 \\
5-6 \\
7-8\end{array}$ & $\begin{array}{r}\text { ve drugs in the inter } \\
49(35.8) \\
205(40.8) \\
13(56.5)\end{array}$ & $\begin{array}{l}\text { ve phase }{ }^{\S} \\
88(64.2) \\
298(59.2) \\
10(43.5)\end{array}$ & $\begin{array}{c}1.00 \\
0.81(0.55-1.20) \\
0.43(0.17-1.05)\end{array}$ & $\begin{array}{l}0.3 \\
0.06\end{array}$ & & \\
\hline $\begin{array}{l}\text { Ofloxacin treatment } \\
\text { No } \\
\text { Yes }\end{array}$ & $\begin{array}{r}246(41.3) \\
21(30.9)\end{array}$ & $\begin{array}{r}349(58.7) \\
47(69.1)\end{array}$ & $\begin{array}{c}1.00 \\
1.58(0.92-2.71)\end{array}$ & 0.1 & & \\
\hline
\end{tabular}

* Wald test.

${ }^{+}$Adjusted for age, sex, previous first-line drug, cavities on X-ray, programme year and number of drugs to which strain is resistant at diagnosis.

* Of 832 patients with PZA DST available at diagnosis, 166 were excluded because they received no PZA in the intensive phase and three due to unknown X-ray results.

‡Two missing values due to unknown smear result.

${ }^{\S}$ Median number of potentially effective drugs per month, except PZA, in the intensive phase, with all drugs counted as 1.

$\mathrm{PZA}=$ pyrazinamide; $\mathrm{LTFU}=$ loss to follow-up; $\mathrm{OR}=$ odds ratio; $\mathrm{Cl}=$ confidence interval; $\mathrm{OOR}=$ adjusted $\mathrm{OR}$; IQR = interquartile range; $\mathrm{TB}=$ tuberculosis; $\mathrm{MDR}-\mathrm{TB}=$ multidrug-resistant TB; XDR-TB = extensively drug-resistant TB; DST = drug susceptibility testing. 
Table A.3 Crude and adjusted analyses of the effect of PZA susceptibility on treatment outcome among patients treated with a full PZA-containing intensive phase and who had bacteriologically confirmed TB:* death/failure model

\begin{tabular}{|c|c|c|c|c|c|c|}
\hline & $\begin{array}{c}\text { Death/failure } \\
n(\%)\end{array}$ & $\begin{array}{l}\text { Success } \\
n(\%)\end{array}$ & OR $(95 \% \mathrm{Cl})$ & $P$ value $^{\dagger}$ & aOR $(95 \% \mathrm{Cl})^{\ddagger}$ & $P$ value $^{\dagger}$ \\
\hline Pyrazinamide & $82 / 368^{\S}(22.3)$ & $286 / 368^{\S}(77.7)$ & & & & \\
\hline Resistant & $60(22.2)$ & $210(77.8)$ & 1.00 & & & \\
\hline Susceptible & $22(21.4)$ & 76 (77.6) & $0.99(0.57-1.72)$ & 1.0 & $0.87(0.48-1.59)$ & 0.7 \\
\hline
\end{tabular}

* Sputum submitted between 30 days before and 7 days after starting treatment.

${ }^{+}$Wald test.

${ }^{\ddagger}$ Adjusted for age, sex, previous first-line drugs, cavities on X-ray, programme year and number of drugs to which strain was resistant at diagnosis

${ }^{\S}$ Of 579 patients with PZA DST result available and bacteriologically confirmed TB, 94 were excluded as they received no PZA in the intensive phase, and 117 due to loss to follow-up.

$\mathrm{PZA}=$ pyrazinamide; $\mathrm{TB}=$ tuberculosis; $\mathrm{OR}=$ odds ratio; $\mathrm{Cl}=$ confidence interval; aOR = adjusted OR; DST = drug susceptibility testing.

Table A.4 Crude and adjusted analyses of the effect of PZA susceptibility on treatment outcome among patients treated with a full PZA-containing intensive phase who had confirmed receipt of at least 6 months of treatment: death/failure model

\begin{tabular}{lcccccc}
\hline & $\begin{array}{c}\text { Death/failure } \\
n(\%)\end{array}$ & $\begin{array}{c}\text { Success } \\
n(\%)\end{array}$ & OR $(95 \% \mathrm{Cl})$ & $P$ value* $^{*}$ & aOR $(95 \% \mathrm{Cl})^{+}$ & $P$ value* \\
\hline Pyrazinamide & $81 / 477^{\ddagger}(17.0)$ & $396 / 477^{\ddagger}(83.0)$ & & & & \\
Resistant & $58(17.2)$ & $280(82.8)$ & 1.00 & & \\
Susceptible & $23(16.5)$ & $116(83.5)$ & $1.04(0.62-1.77)$ & 0.9 & $0.97(0.54-1.74)$ & 0.9 \\
\hline
\end{tabular}

* Wald test.

${ }^{+}$Adjusted for age, sex, previous first-line drugs, cavities on X-ray, programme year and number of drugs to which strain was resistant at diagnosis. Model with PZA-resistant strains at diagnosis: also adjusted for previous outcome.

${ }^{\ddagger}$ Of 667 patients with PZA DST result available who had at least 6 months of total treatment, 135 were excluded beacause they received no PZA in the intensive phase, 1 due to unknown $\mathrm{X}$-ray results and 54 due to loss to follow-up.

$\mathrm{PZA}=$ pyrazinamide; $\mathrm{OR}=$ odds ratio; $\mathrm{Cl}=$ confidence interval; $\mathrm{aOR}=$ adjusted $\mathrm{OR} ; \mathrm{DST}=$ drug susceptibility testing.

Table A.5 Crude and adjusted analyses of the effect of PZA susceptibility on treatment outcome among patients treated with a full PZA-containing intensive phase who started in the 2012 programme: death/failure model

\begin{tabular}{|c|c|c|c|c|c|c|}
\hline & $\begin{array}{c}\text { Death/failure } \\
n(\%)\end{array}$ & $\begin{array}{c}\text { Success } \\
n(\%)\end{array}$ & OR $(95 \% \mathrm{Cl})$ & $P$ value* & $\mathrm{aOR}(95 \% \mathrm{Cl})^{\dagger}$ & $P$ value* \\
\hline Pyrazinamide & $58 / 294^{\ddagger}(19.7)$ & $236 / 294^{\neq}(80.3)$ & & & & \\
\hline Resistant & $44(20.4)$ & $172(79.6)$ & 1.00 & & & \\
\hline Susceptible & $14(17.6)$ & $64(82.1)$ & $1.17(0.60-2.28)$ & 0.6 & $1.03(0.51-2.08)$ & 0.9 \\
\hline
\end{tabular}

* Wald test.

${ }^{\dagger}$ Adjusted for age, sex, previous first-line drugs, cavities on X-ray, programme year and number of drugs to which strain was resistant at diagnosis. Model with PZA-resistant strains at diagnosis: also adjusted for previous outcome.

${ }^{\ddagger}$ Of 410 patients with PZA DST results available who started in the 2012 programme, 24 were excluded because they did not receive PZA in the intensive phase and 92 because they were lost to follow-up.

$\mathrm{PZA}=$ pyrazinamide; $\mathrm{OR}=$ odds ratio; $\mathrm{Cl}=$ confidence interval; $\mathrm{aOR}=$ adjusted $\mathrm{OR} ; \mathrm{DST}=$ drug susceptibility testing. 
Table A.6 Crude and adjusted analyses of effect of PZA regimen received on treatment outcome among patients with no available PZA DST results at diagnosis and among patients with PZA-resistant strains at diagnosis: two PZA treatment duration models

\begin{tabular}{|c|c|c|c|c|c|c|}
\hline & $\begin{array}{c}\text { Death/failure } \\
n(\%)\end{array}$ & $\begin{array}{l}\text { Success } \\
n(\%)\end{array}$ & OR $(95 \% \mathrm{Cl})$ & $P$ value* & $\mathrm{aOR}(95 \% \mathrm{Cl})^{\dagger}$ & $P$ value* \\
\hline PZA DST results at diagnosis not available & $247 / 1114^{\ddagger}(22.2)$ & $867 / 1114^{\ddagger}(77.8)$ & & & & \\
\hline \multicolumn{7}{|l|}{ Partial and full PZA regimen } \\
\hline Partial ( $<80 \%$ in the intensive phase) & $18(18.9)$ & $77(81.1)$ & 1.00 & & & \\
\hline $\begin{array}{l}\text { Full PZA regimen }(\geqslant 80 \% \text { in the } \\
\text { intensive phase) }\end{array}$ & $229(22.5)$ & $790(77.5)$ & $0.81(0.47-1.38)$ & 0.4 & $0.86(0.9-1.51)$ & 0.6 \\
\hline \multicolumn{7}{|c|}{ None, incomplete and full PZA regimen in the intensive phase } \\
\hline None $(<16 \% \text { in the intensive phase })^{\S}$ & $14(18.4)$ & $62(81.6)$ & 1.00 & & & \\
\hline Incomplete $(\geqslant 16 \% \text { and }<80 \%)^{\text {I }}$ & $4(21.1)$ & $15(78.9)$ & $0.85(0.24-2.94)$ & 0.8 & $0.80(0.22-2.94)$ & 0.7 \\
\hline $\begin{array}{l}\text { Full PZA regimen }(\geqslant 80 \% \text { in the } \\
\text { intensive phase) }\end{array}$ & $229(22.5)$ & $790(77.5)$ & $0.78(0.43-1.42)$ & 0.4 & $0.82(0.43-1.55)$ & 0.5 \\
\hline PZA-resistant strains at diagnosis & $119 / 480^{\#}(24.8)$ & $361 / 480(75.2)$ & & & & \\
\hline \multicolumn{7}{|l|}{ Partial and full PZA regimen } \\
\hline Partial ( $<80 \%$ in the intensive phase) & $39(32.5)$ & $81(67.5)$ & 1.00 & & & \\
\hline $\begin{array}{l}\text { Full PZA regimen }(\geqslant 80 \% \text { in the } \\
\text { intensive phase) }\end{array}$ & $80(22.2)$ & $280(77.8)$ & $1.69(1.07-2.66)$ & 0.03 & $1.38(0.71-2.68)$ & 0.3 \\
\hline \multicolumn{7}{|c|}{ None, incomplete and full PZA regimen** in the intensive phase } \\
\hline None $(<16 \% \text { in the intensive phase })^{\S}$ & $12(27.3)$ & $32(72.7)$ & 1.00 & & & \\
\hline Incomplete $(\geqslant 16 \% \text { and }<80 \%)^{q}$ & $27(35.5)$ & $49(64.5)$ & $0.68(0.30-1.53)$ & 0.4 & $0.51(0.20-1.32)$ & 0.2 \\
\hline $\begin{array}{l}\text { Full PZA regimen }(\geqslant 80 \% \text { in the } \\
\text { intensive phase) }\end{array}$ & $80(22.2)$ & $280(77.8)$ & $1.31(0.65-2.67)$ & 0.5 & $0.80(0.29-2.23)$ & 0.7 \\
\hline
\end{tabular}

\section{* Wald test.}

${ }^{+}$Adjusted for age, sex, previous first-line drugs, cavities on X-ray, programme year and number of drugs to which strain was resistant at diagnosis.

${ }^{\ddagger}$ Of 1614 patients with no available PZA DST at diagnosis; 157 excluded as PZA DST had not been defined as diagnostic before starting treatment; four because they were given PZA treatment only in the continuation phase; and 339 due to LTFU.

$\S<16 \%$ of days in the intensive phase (equivalent to $<30$ days in a 6 -month intensive phase).

" $\geqslant 16 \%$ but $<80 \%$ of days in the intensive phase

\# Of 612 patients with PZA-resistant MDR-TB strains at diagnosis, 127 excluded due to outcome LTFU and five patients due to unknown X-ray result out. **Also adjusted for median potentially effective drugs in the intensive phase.

$\mathrm{PZA}=$ pyrazinamide; $\mathrm{DST}=$ drug susceptibility testing; $\mathrm{OR}=$ odds ratio; $\mathrm{Cl}=$ confidence interval; $\mathrm{aOR}=$ adjusted $\mathrm{OR} ; \mathrm{MDR}-\mathrm{TB}=$ multidrug-resistant tuberculosis; LTFU = loss to follow-up.

Table A.7 Crude and adjusted analyses of the effect of PZA regimen received on treatment outcome among patients with no PZA DST result available at diagnosis and among patients with PZA-resistant strains at diagnosis: two PZA treatment length models

\begin{tabular}{|c|c|c|c|c|c|c|}
\hline & $\begin{array}{c}\text { Death/failure/LTFU } \\
n(\%)\end{array}$ & $\begin{array}{l}\text { Success } \\
n(\%)\end{array}$ & OR $(95 \% \mathrm{Cl})$ & $P$ value* & $\mathrm{aOR}(95 \% \mathrm{Cl})^{\dagger}$ & $P$ value* \\
\hline PZA DST result at diagnosis not available & $586 / 1453^{\ddagger}(40.3)$ & $867 / 1453^{\ddagger}(59.7)$ & & & & \\
\hline \multicolumn{7}{|l|}{ Partial and full PZA regimen } \\
\hline Partial (<80\% in the intensive phase) & $48(38.4)$ & 77 (61.6) & 1.00 & & & \\
\hline $\begin{array}{l}\text { Full PZA regimen ( } \geqslant 80 \% \text { in the } \\
\text { intensive phase) }\end{array}$ & $538(40.5)$ & $790(59.5)$ & $0.92(0.63-1.33)$ & 0.6 & $0.95(0.63-1.41)$ & 0.8 \\
\hline \multicolumn{7}{|c|}{ None, incomplete and full PZA regimen in the intensive phase } \\
\hline None $(<16 \% \text { in the intensive phase })^{\S}$ & $35(36.1)$ & $62(63.9)$ & 1.00 & & & \\
\hline Incomplete $(\geqslant 16 \% \text { and }<80 \%)^{n}$ & $13(46.4)$ & 15 (53.6) & $0.65(0.28-1.52)$ & 0.3 & $0.59(0.24-1.42)$ & 0.2 \\
\hline $\begin{array}{l}\text { Full PZA regimen ( } \geqslant 80 \% \text { in the } \\
\text { intensive phase) }\end{array}$ & $538(40.5)$ & $790(59.5)$ & $0.83(0.54-1.27)$ & 0.4 & $0.84(0.53-1.31)$ & 0.4 \\
\hline PZA-resistant strains at diagnosis & $246 / 607^{\#}(40.5)$ & $361 / 607^{\#}(59.5)$ & & & & \\
\hline \multicolumn{7}{|l|}{ Partial and full PZA regimen } \\
\hline Partial ( $<80 \%$ in the intensive phase) & $58(41.7)$ & $81(58.3)$ & 1.00 & & & \\
\hline $\begin{array}{l}\text { Full PZA regimen ( } \geqslant 80 \% \text { in the } \\
\text { intensive phase) }\end{array}$ & $188(40.2)$ & $280(59.8)$ & $1.07(0.73-1.57)$ & 0.7 & $1.14(0.66-1.96)$ & 0.6 \\
\hline \multicolumn{7}{|c|}{ None, incomplete and full PZA regimen in the intensive phase } \\
\hline None $(<16 \% \text { in the intensive phase })^{\S}$ & $17(34.7)$ & $32(65.3)$ & 1.00 & & & \\
\hline Incomplete $(\geqslant 16 \% \text { and }<80 \%)^{n}$ & $41(45.6)$ & 49 (54.4) & $0.63(0.31-1.30)$ & 0.2 & $0.61(0.27-1.36)$ & 0.2 \\
\hline $\begin{array}{l}\text { Full PZA regimen ( } \geqslant 80 \% \text { in the } \\
\text { intensive phase) }\end{array}$ & $188(40.2)$ & $280(59.8)$ & $0.79(0.43-1.47)$ & 0.5 & $0.77(0.33-1.78)$ & 0.5 \\
\hline
\end{tabular}

* Wald test.

${ }^{+}$Adjusted for age, sex, previous first-line drugs, cavities on X-ray, programme year and number of drugs to which strain was resistant at diagnosis. Model with PZA-resistant strains at diagnosis: also adjusted for previous outcome.

* 157 excluded as PZA DST had not been defined as diagnostic before starting treatment and four because they were given PZA treatment only in the continuation phase.

$\S<16 \%$ of days in the intensive phase (equivalent to $<30$ days in a 6 -month intensive phase period).

$\eta 16 \%$ but $<80 \%$ of days in the intensive phase.

\# Five patients excluded due to unknown $X$-ray results.

PZA = pyrazinamide; LTFU = loss to follow-up; OR = odds ratio; $\mathrm{Cl}=$ confidence interval; aOR = adjusted OR; DST = drug susceptibility testing 
Contexte: L'Organisation Mondiale de la Santé (OMS) recommande l'inclusion du pyrazinamide (PZA) dans les protocoles de traitement de la tuberculose multirésistante (TB-MDR) sauf si la résistance au PZA est certaine.

OBJECTIF : Examiner l'association entre sensibilité au PZA et résultat du traitement de la TB-MDR parmi les patients traités avec un protocole PZA et voir si la durée de la phase intensive du traitement par PZA a affecté les résultats du traitement.

SCHÉMA : Nous avons réalisé une étude rétrospective de cohorte, incluant tous les patients TB-MDR éligibles ayant commencé leur traitement en 2003-2013 au sein du programme TB à Karakalpakstan, Ouzbékistan. Le test de pharmacosensibilité (DST) au PZA a recouru à la culture en milieu liquide et les résultats ont été classés en fonction des définitions 2013 de l'OMS.
RÉSULTATS : Sur 2446 patients TB-MDR inclus, 832 $(34,0 \%)$ disposaient d'un DST au PZA de départ, dont $612(73,6 \%)$ ont été résistants au PZA. Nous n’avons pas trouvé d'association entre le succès du traitement et la sensibilité au PZA (OR ajusté [ORa] 0,86 ; IC95\% $0,51-1,44 ; P=0,6)$ chez les patients traités par PZA. De plus, aucune preuve n'a mis en évidence une association entre succès du traitement et durée du traitement par PZA (ORa 0,86; IC95\% 0,49-1,51; $P=0,6$ ) parmi les patients sans DST au PZA de départ.

CONCLUSION : Le traitement de la TB-MDR avec un protocole standard de PZA ne semble pas améliorer les résultats du traitement, quelles que soient la sensibilité au PZA ou la durée du traitement.
MARCO De REFERENCIA: La Organización Mundial de la Salud (OMS) recomienda que se incluya la pirazinamida (PZA) en las pautas de tratamiento de la tuberculosis multirresistente (TB-MDR), a menos de que exista certeza sobre la resistencia.

O B JETIV O: Investigar la asociación entre la sensibilidad a la PZA y el desenlace del tratamiento de la TB-MDR en los pacientes que reciben una pauta con PZA y determinar si la duración de la fase intensiva del tratamiento con PZA tiene algún efecto sobre el desenlace terapéutico.

MÉTODO: Se llevó a cabo un estudio de cohortes retrospectivo de todos los pacientes con TB-MDR que cumplían los requisitos y habían iniciado tratamiento del 2003 al 2013 en el marco del programa contra la tuberculosis en Karakalpakistán, en Uzbekistán. Se practicó la prueba de sensibilidad a PZA en medio líquido y los desenlaces se clasificaron según las definiciones de la OMS del 2013.
RESULTADOS: De los 2446 pacientes con TB-MDR incluidos, 832 contaban con una prueba inicial de sensibilidad a PZA (34,0\%) y de ellos, 612 eran resistentes a PZA $(73,6 \%)$. No se observó ninguna asociación entre el éxito terapéutico y la sensibilidad a PZA en los pacientes que recibieron un tratamiento con PZA (OR ajustado [ORa] 0,86; IC95\% 0,51-1,44; $P=$ $0,6)$. Además, no se encontraron indicios de una asociación entre el éxito terapéutico y la duración del tratamiento con PZA en los pacientes que no contaban con una prueba inicial de resistencia a PZA (ORa 0,86; IC95\% 0,49-1,51; $P=0,6$ ).

CONCLUSIÓN: El tratamiento de la TB-MDR con una pauta corriente que contiene PZA no parece mejorar los desenlaces terapéuticos, sea cual fuere la situación frente a la sensibilidad a PZA o la duración de su administración. 